\title{
The Indolic Diet-Derivative, 3,3'-Diindolylmethane, Induced Apoptosis in Human Colon Cancer Cells through Upregulation of NDRG1
}

\author{
A. Lerner, ${ }^{1,2}$ M. Grafi-Cohen, ${ }^{1,2}$ T. Napso, ${ }^{3}$ N. Azzam, ${ }^{4}$ and F. Fares ${ }^{4,5}$ \\ ${ }^{1}$ Pediatric Gastroenterology and Nutrition Unit, Carmel Medical Center, Haifa 34362, Israel \\ ${ }^{2}$ B. Rappaport School of Medicine, Technion-Israel Institute of Technology, Haifa 31096, Israel \\ ${ }^{3}$ Department of Evolutionary and Environmental Biology, University of Haifa, Mount Carmel, Haifa 31905, Israel \\ ${ }^{4}$ Department of Human Biology, University of Haifa, Mount Carmel, Haifa 31905, Israel \\ ${ }^{5}$ Department of Molecular Genetics, Carmel Medical Center, Haifa 34362, Israel
}

Correspondence should be addressed to F. Fares, ffares@sci.haifa.ac.il

Received 31 July 2011; Accepted 29 August 2011

Academic Editor: Masa-Aki Shibata

Copyright () 2012 A. Lerner et al. This is an open access article distributed under the Creative Commons Attribution License, which permits unrestricted use, distribution, and reproduction in any medium, provided the original work is properly cited.

\begin{abstract}
$\mathrm{N}$-myc downstream regulated gene-1 participates in carcinogenesis, angiogenesis, metastases, and anticancer drug resistance. In the present study, we analyzed the expression pattern of N-myc downstream regulated gene-1 following treatment of human colonic cancer cell lines; HCT-116 (well differentiated with wild-type p53 gene) and Colo-320 (poorly differentiated with mutant p53 gene), with 3,3'-diindolylmethane, a well-established proapoptotic agent product derived from indole-3-carbinol. Treatment of Colo-320 and HCT-116 with 3,3'-diindolylmethane disclosed inhibition of cell viability in a dose-dependent manner, mediated through apoptosis induction. The increased expression of $\mathrm{N}$-myc downstream regulated gene-1 was detected only in poorly differentiated colon cancer cells, Colo-320 cell line. Our results suggest that N-myc downstream regulated gene-1 expression is enhanced by $3,3^{\prime}$-diindolylmethane in poorly differentiated cells and followed by induction of apoptosis. 3,3'-diindolylmethane induced apoptosis may represent a new regulator of $\mathrm{N}$-myc downstream regulated gene- 1 in poorly differentiated colonic cancer cells.
\end{abstract}

\section{Introduction}

$\mathrm{N}$-myc downstream regulated 1 gene (NDRG1) is a 43 $\mathrm{kDa}$ protein located mainly in the cytoplasm but occasionally translocates into the nucleus in a p53-dependent manner [1]. This protein interacts with many cell elements and consequently participates in various processes in the cells, such as differentiation, response to stress conditions, involvement in carcinogenesis, angiogenesis, and metastasis. NDRG1 is induced, among others, by stress conditions, inhibition of DNA methylation, and histone deacetylation [2-7]. Furthermore, NDRG1 is necessary for caspase-3 activation and is required for p53-dependent apoptosis in a cell type-specific manner [8]. Nevertheless, the precise function of NDRG1 and its regulation in cancer cells is far from being clear.

In colon cancer, NDRG1 protein levels appear to be decreased with the progression from normal colonic epithe- lium to carcinoma $[9,10]$. Moreover, NDRG1 expression is associated with a more aggressive tumor phenotype and poor outcome in colorectal cancer [11].

NDRG1 mediates apoptosis in several tissues $[8,12$, 13]. However, the regulation of NDRG1 during apoptosis state in cancer cells in general, and in colon cancer in particular, was not explored previously. The purpose of the current study was to investigate the NDRG1 expression pattern in human colon cancer cell lines which vary in their differentiation level and in their p53 status. For apoptosis induction, we used 3,3' -diindolylmethane (DIM), a well-established proapoptotic agent product derived from indole-3-carbinol (I3C). In a low environmental pH, I3C is converted into polymeric products, among which 3,3'diindolylmethane (DIM) is the main one. Studies showed that DIM induced cell-cycle arrest in human prostate cancer through, the upregulation of cycline-dependent kinases [14] and apoptosis via mitochondrial pathway [15-21]. 


\section{Materials and Methods}

2.1. Cell Culture and Treatment. Two human colon cancer cell lines HCT-116 (well differentiated, p53 wild type) and Colo-320 (poorly differentiated, p53 mutant) were grown in a medium $10 \%$ fetal calf serum and $100 \mathrm{U} / \mathrm{mL}$ penicillinstreptomycin in the presence of DIM $(10-100 \mu \mathrm{M})$. Cell viability (XTT) [22], cytotoxicity, and leakage of lactate dehydrogenase $[23,24]$ were tested 24,48 , and 72 hours after treatment.

DAPI staining for visualization of chromatin condensation [25] were conducted after treatment with $60 \mu \mathrm{M}$ DIM for $72 \mathrm{hr}[26]$.

2.2. RNA Isolation and Real-Time PCR. RNA from colon cancer cells was isolated using Tri-reagent (Tal-Ron). Total RNA $(3 \mu \mathrm{g})$ was reverse-transcribed to cDNA. $1197 \mathrm{bp}$ product of NDRG1 was amplified by real-time PCR (ABI Prism 7900) using probe and the following primers: $5^{\prime}$-AGGGACATGTCTCGGGAGATGCAGGAT-3' and $5^{\prime}$-GGCCGCCTAGCAGGAGACCTCCATGG-3'. As a control gene, we amplified $\beta$-actin (838 bp) with $5^{\prime}$ ATCTGGCACCACACCTTCTACAATGAGCTGCG- $3^{\prime}$ and $5^{\prime}$-CGTCATACTCCT GCTTGCTGATCCACATCTGC-3' .

Alkaline phosphatase activity assay [27] was conducted 4 and $8 \mathrm{~h}$ after treatment with $60 \mu \mathrm{M}$ DIM.

2.3. Statistical Analysis. Data analyses were carried out using SPSS version 17. Experiments were repeated three times, each performed in triplicate, and the data are presented as means \pm SD (Standard Deviation). Statistical analysis of the differences between controls and treated groups were performed using Student's $t$-test. $P<0.05$ was considered significant.

\section{Results}

3.1. DIM Reduced Cell Viability by Apoptosis Induction. We observed that the two colon cancer cells treated with DIM $(10-80 \mu \mathrm{M})$ for $72 \mathrm{hr}$ had a significant inhibitory effect $(P<$ 0.001 ) in a dose-dependent manner (Figure 1 ). The $\mathrm{IC}_{50}$ values were $52 \mu \mathrm{M}$ for HCT-116 and $56 \mu \mathrm{M}$ for Colo-320. Furthermore, no toxic effects were manifested for these concentrations, as it was determined with LDH enzyme activity (Data not shown).

Following the reduced viability, apoptosis was tested in cells treated with DIM $(60 \mu \mathrm{M})$ for $72 \mathrm{hr}$ (Figure 2(a)). Both cell lines showed DNA fragmentation, a main feature of apoptosis occurrence. In addition, cell treatment with $60 \mu \mathrm{M}$ DIM for $48 \mathrm{~h}$ followed by DAPI staining (Figure 2(b)) showed apoptotic cells that exhibited typical apoptotic morphology, condensation, and fragmentation of the nucleus, in comparison to untreated cells.

3.2. Alteration in NDRG1 Expression in Colo 320. Basal expression of NDRG1 prior treatment showed low levels of mRNA and no expression of protein in Colo 320 cell lines;

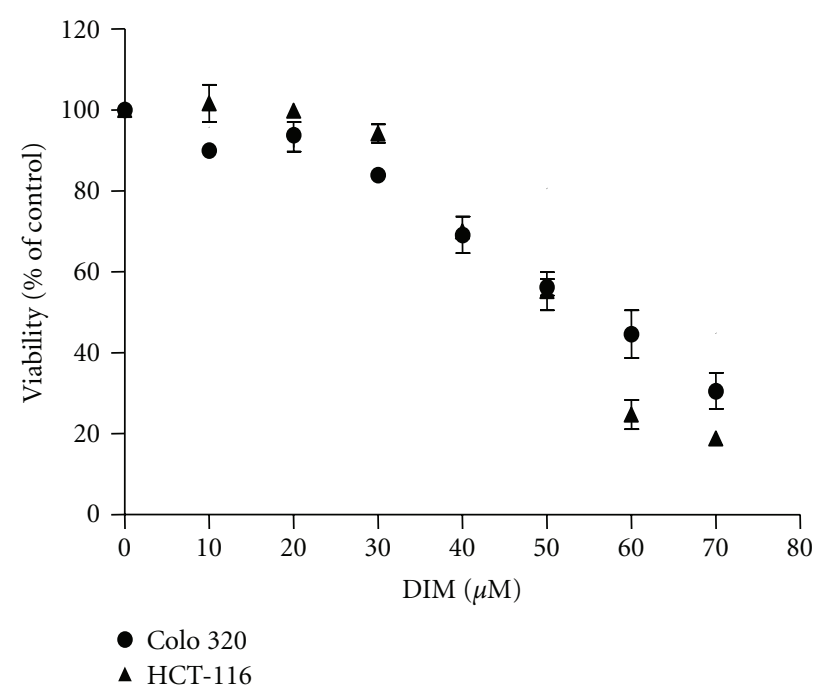

Figure 1: Effect of DIM on cell viability. Exponentially growing cells were incubated in the presence of 10 to $100 \mu \mathrm{M}$ of DIM for 72 hours, and the viable cells were detected by XTT assay. The results are presented as percentage of control and expressed as means \pm SD of three independent experiments.

alternatively, high levels of both mRNA and protein were detected in HCT-116 cell line (Data not shown).

Exposure of the Colo 320 to DIM for $24-72 \mathrm{hr}$ resulted in a significant increase (9-fold for $24 \mathrm{~h}, 10$-fold for $48 \mathrm{~h}$, and 15 -fold for $72 \mathrm{~h}$ following treatment) of the NDRG1 mRNA levels (Figure 3). However, exposure of HCT-116 to DIM resulted in uninfluenced expression of the NDRG1 mRNA compared to control cells.

\subsection{Effect of DIM and NDRG1 Expression on Cell Differenti-} ation. Alkaline phosphatase activity, a molecular marker of colon epithelial cells differentiation was used to determine whether the increase in NDRG1 expression is related to differentiation alteration in the cells. The results revealed that treated cells had a nonsignificant increase of alkaline phosphatase activity in Colo 320 cells and had no effect in HCT-116 cells (Figure 4).

\section{Discussion}

In the present study, we examined NDRG1 expression in human colon cancer cells during apoptosis induced upon DIM application. First, we showed that indol derivative found in crucifers (DIM) induced apoptosis in both human colon cancer cells HCT-116 and Colo 320. We have previously shown that DIM has a suppressive effect on the growth of breast cancer and prostate cell lines $[15,16,20]$. The $\mathrm{IC}_{50}$ values for DIM on growth inhibition of colon cancer cells $(50-60 \mu \mathrm{M})$ were similar to those found for prostate and breast cancer cells $(20-40 \mu \mathrm{M}$ and $17-30 \mu \mathrm{M}$, resp.) $[15,28]$. DIM affected the viability of the cancer cell in a time- and dose-dependent manner irrespective of their p53 phenotype. The effect was mediated by apoptosis as shown morphologically and by DNA fragmentation. Thus, colonic 


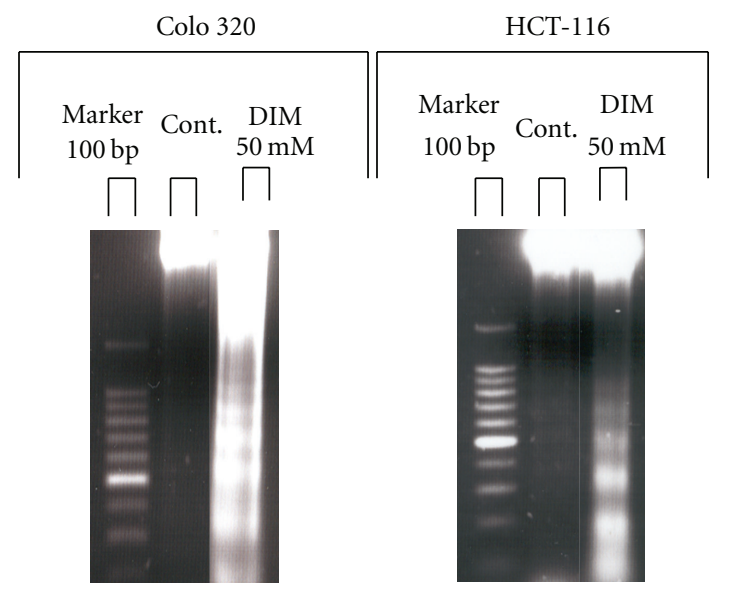

(a)

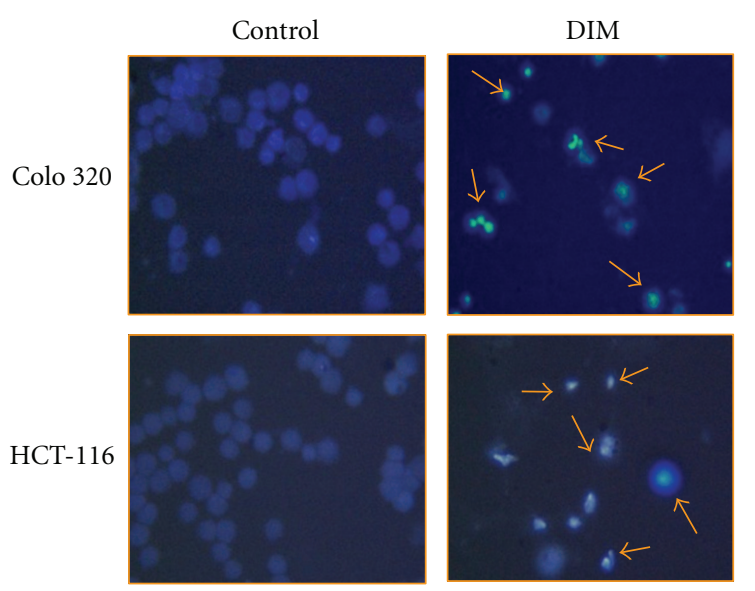

(b)

Figure 2: Apoptosis formation by DIM in Colo 320 and HGT116 cell lines. Cells were treated with DIM $60 \mu \mathrm{M}$ for 72 hours. DNA was extracted and separated on a 1.5\% Agarose gel. The data shown were repeated three times (a). Morphologic changes, denoting apoptotic cells were shown by cell morphological changes. Cells were incubated in the presence of $60 \mu \mathrm{M}$ DIM for 48 hours and stained with DAPI. Morphologic changes are shown by arrows (b). The data shown were repeated three times.

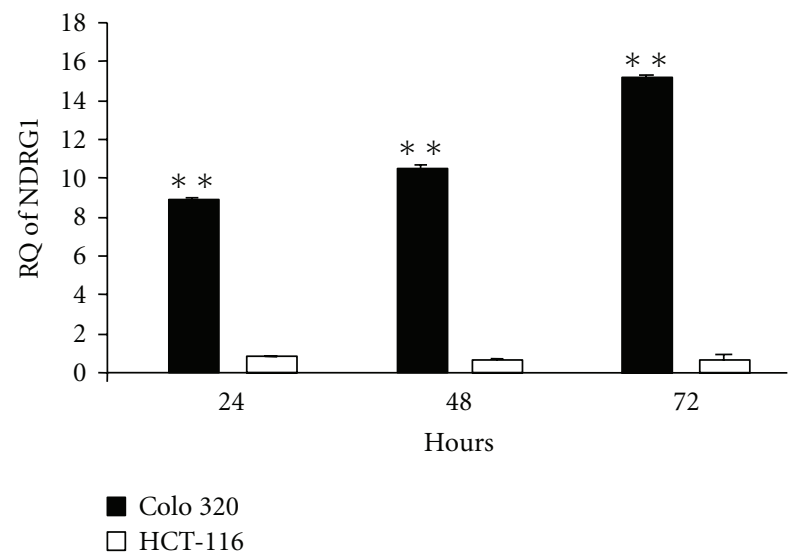

Figure 3: Expression of NDRG1. Cells treated with $60 \mu \mathrm{M}$ DIM for 24,48 and $72 \mathrm{~h}$. The levels of mRNA were examined by real-time PCR and are represented as RQ (relative quantification) $=2^{-\mathrm{ddCt}}$. ${ }^{*} P$ value $<0.01,{ }^{* *} P$ value $<0.001$.

cell lines can be added to an increasing list of other organs' cell lines, namely, prostate and breast $[16,21,29]$ that are affected by environmental factors which induce apoptosis.

The basal expression of NDRG1 reported here, high levels in well-differentiated cells (HCT-116) and low levels in poorly differentiated cells (Colo-320), was reported in colon [30], gastric cancer specimens [31], and in esophageal squamous cell carcinoma [32].

Quantization of NDRG1 expression showed that NDRG1 mRNA is increased 9-15-fold $(P<0.001)$ during treatment of the Colo-320 cells with DIM for 24-72 hr compared to control cells, indicating NDRG1 upregulation during apoptosis induced by DIM.

Up to now, it was known that NDRG1 expression is induced by DNA damage in a p53-dependent fashion, and it is necessary but not sufficient for p53-mediated caspase

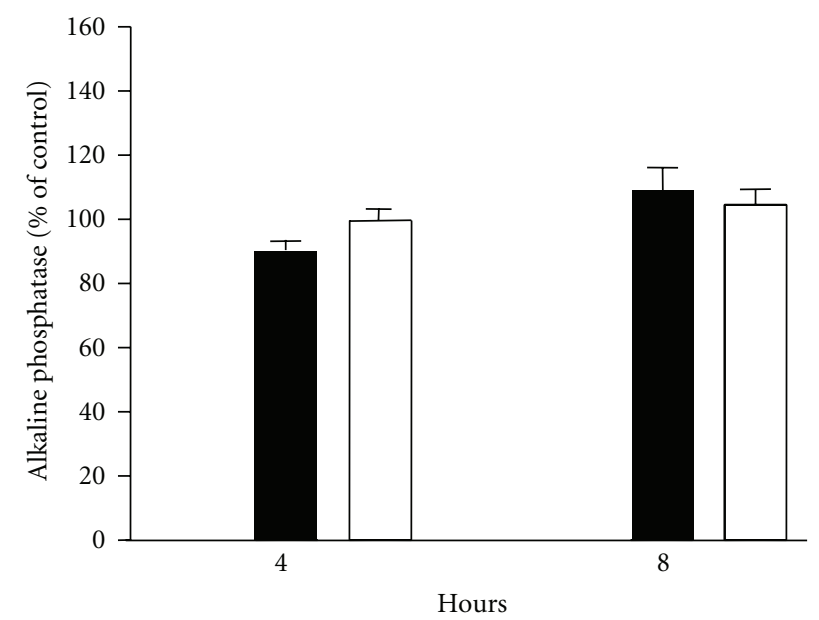

Colo 320

HCT-116

FIGURE 4: DIM treatment effect on alkaline phosphatase activity. Alkaline phosphatase activity (differentiation factor of colon cells) was detected after 4 and 8 hours of treatment. The results are presented as percentage of control and expressed as means \pm SD of three independent experiments. ${ }^{* *} P$ value $<0.001$.

activation and apoptosis [8]. The present study shows for the first time that DIM increased NDRG1 expression in a p53 independent pathway followed by induction of apoptosis.

In conclusion, in this study, we provide evidence that the indole diet-derived DIM induce apoptosis in two human colon cancer cell lines, well- and poorly differentiated. However, induction of apoptosis by DIM is followed by increased NDRG1 expression only in a poorly differentiated and p53 mutant cells. On the other hand, DIM induced apoptosis in well-differentiated cells in a NDRG1-independent pathway. Our results may contribute to a better understanding of the 
molecular mechanisms by which DIM exerts its effects in colon cancer cells and tumors. It is suggested that NDRG1 is not only a differentiation factor but might impact the apoptotic process. In all the NDRG1 transfection studies, apoptotic effects should be taken in account. In fact, NDRG1 is on the list of metastatic-related/cancer suicide genes drug development in the battle against cancer [33, 34]. Further studies are needed in order to examine NDRG1 role in colon cancer genesis. Results from the present research may contribute to the development of new and efficient strategies for colon cancer therapy.

\section{Conflict of Interests}

The authors declare no potential conflict of interests with respect to the authorship and/or publication of this paper.

\section{References}

[1] S. K. Kurdistani, P. Arizti, C. L. Reimer, M. M. Sugrue, S. A. Aaronson, and S. W. Lee, "Inhibition of tumor cell growth by RTP/rit42 and its responsiveness to p53 and DNA damage," Cancer Research, vol. 58, no. 19, pp. 4439-4444, 1998.

[2] T. P. Ellen, Q. Ke, P. Zhang, and M. Costa, "NDRG1, a growth and cancer related gene: regulation of gene expression andfunction in normal and disease states," Carcinogenesis, vol. 29, no. 1, pp. 2-8, 2008.

[3] K. Kokame, H. Kato, and T. Miyata, "Homocysteinerespondent genes in vascular endothelial cells identified by differential display analysis: GRP78/BiP and novel genes," Journal of Biological Chemistry, vol. 271, no. 47, pp. 2965929665, 1996.

[4] H. Park, M. A. Adams, P. Lachat, F. Bosman, S. C. Pang, and C. H. Graham, "Hypoxia induces the expression of a 43-kDa protein (PROXY-1) in normal and malignant cells," Biochemical and Biophysical Research Communications, vol. 276, no. 1, pp. 321-328, 2000.

[5] W. Ulrix, J. V. Swinnen, W. Heyns, and G. Verhoeven, "The differentiation-related gene 1, Drg1, is markedly upregulated by androgens in LNCaP prostatic adenocarcinoma cells," FEBS Letters, vol. 455, no. 1-2, pp. 23-26, 1999.

[6] D. Zhou, K. Salnikow, and M. Costa, "Cap43, a novel gene specifically induced by Ni2+ compounds," Cancer Research, vol. 58, no. 10, pp. 2182-2189, 1998.

[7] A. Kitowska and T. Pawełczyk, "N-myc downstream regulated 1 gene and its place in the cellular machinery," Acta Biochimica Polonica, vol. 57, no. 1, pp. 15-21, 2010.

[8] S. Stein, E. K. Thomas, B. Herzog et al., "NDRG1 is necessary for p53-dependent apoptosis," Journal of Biological Chemistry, vol. 279, no. 47, pp. 48930-48940, 2004.

[9] H. Cangul, "Hypoxia upregulates the expression of the NDRG1 gene leading to its overexpression in various human cancers," BMC Genetics, vol. 5, article 27, 2004.

[10] M. A. Shah, N. Kemeny, A. Hummer et al., "Drg1 expression in 131 colorectal liver metastases: correlation with clinical variables and patient outcomes," Clinical Cancer Research, vol. 11, no. 9, pp. 3296-3302, 2005.

[11] B. Strzelczyk, A. Szulc, R. Rzepko et al., "Identification of highrisk stage II colorectal tumors by combined analysis of the NDRG1 gene expression and the depth of tumor invasion," Annals of Surgical Oncology, vol. 16, no. 5, pp. 1287-1294, 2009.
[12] E. Angst, D. W. Dawson, D. Stroka et al., "N-myc downstream regulated gene-1 expression correlates with reduced pancreatic cancer growth and increased apoptosis in vitro and in vivo," Surgery, vol. 149, no. 5, pp. 614-624, 2011.

[13] X. Yan, M. S. Chua, H. Sun, and S. So, "N-Myc down-regulated gene 1 mediates proliferation, invasion, and apoptosis of hepatocellular carcinoma cells," Cancer Letters, vol. 262, no. 1, pp. 133-142, 2008.

[14] O. I. Vivar, C. L. Lin, G. L. Firestone, and L. F. Bjeldanes, " 3,3 '-Diindolylmethane induces a G1 arrest in human prostate cancer cells irrespective of androgen receptor and p53 status," Biochemical Pharmacology, vol. 78, no. 5, pp. 469-476, 2009.

[15] X. Ge, S. Yannai, G. Rennert, N. Gruener, and F. A. Fares, "3,3'-diindolylmethane induces apoptosis in human cancer cells," Biochemical and Biophysical Research Communications, vol. 228, no. 1, pp. 153-158, 1996.

[16] F. A. Fares, X. Ge, S. Yannai, and G. Rennert, "Dietary indole derivatives induce apoptosis in human breast cancer cells," Advances in Experimental Medicine and Biology, vol. 451, pp. 153-157, 1998.

[17] C. Bonnesen, I. M. Eggleston, and J. D. Hayes, "Dietary indoles and isothiocyanates that are generated from cruciferous vegetables can both stimulate apoptosis and confer protection against DNA damage in human colon cell lines," Cancer Research, vol. 61, no. 16, pp. 6120-6130, 2001.

[18] D. Z. Chen, M. Qi, K. J. Auborn, and T. H. Carter, "Indole3-carbinol and diindolylmethane induce apoptosis of human cervical cancer cells and in murine HPV16-transgenic preneoplastic cervical epithelium," Journal of Nutrition, vol. 131, no. 12, pp. 3294-3302, 2001.

[19] S. R. Chinni, Y. Li, S. Upadhyay, P. K. Koppolu, and F. H. Sarkar, "Indole-3-carbinol (I3C) induced cell growth inhibition, G1 cell cycle arrest and apoptosis in prostate cancer cells," Oncogene, vol. 20, no. 23, pp. 2927-2936, 2001.

[20] M. Nachshon-Kedmi, S. Yannai, A. Haj, and F. A. Fares, "Indole-3-carbinol and 3,3'-diindolylmethane induce apoptosis in human prostate cancer cells," Food and Chemical Toxicology, vol. 41, no. 6, pp. 745-752, 2003.

[21] M. Nachshon-Kedmi, F. A. Fares, and S. Yannai, "Therapeutic activity of 3,3' -diindolylmethane on prostate cancer in an in vivo model," Prostate, vol. 61, no. 2, pp. 153-160, 2004.

[22] T. Mosmann, "Rapid colorimetric assay for cellular growth and survival: application to proliferation and cytotoxicity assays," Journal of Immunological Methods, vol. 65, no. 1-2, pp. 55-63, 1983.

[23] A. R. Goeptar, E. J. Groot, H. Scheerens, J. N. M. Commandeur, and N. P. E. Vermeulen, "Cytotoxicity of mitomycin C and Adriamycin in freshly isolated rat hepatocytes: the role of cytochrome P450," Cancer Research, vol. 54, no. 9, pp. 24112418, 1994.

[24] J. H. Moran and R. G. Schnellmann, "A rapid $\beta$-NADH-linked fluorescence assay for lactate dehydrogenase in cellular death," Journal of Pharmacological and Toxicological Methods, vol. 36, no. 1, pp. 41-44, 1996.

[25] P. M. O'Connor, K. Wassermann, M. Sarang, I. Magrath, V. A. Bohr, and K. W. Kohn, "Relationship between DNA crosslinks, cell cycle, and apoptosis in Burkitt's lymphoma cell lines differing in sensitivity to nitrogen mustard," Cancer Research, vol. 51, no. 24, pp. 6550-6557, 1991.

[26] B. Almog, O. Fainaru, R. Gamzu et al., "Placental apoptosis in discordant twins," Placenta, vol. 23, no. 4, pp. 331-336, 2002.

[27] G. A. Turowski, Z. Rashid, F. Hong, J. A. Madri, and M. D. Basson, "Glutamine modulates phenotype and stimulates 
proliferation in human colon cancer cell lines," Cancer Research, vol. 54, no. 22, pp. 5974-5980, 1994.

[28] M. Nachshon-Kedmi, S. Yannai, A. Haj, and F. A. Fares, "Indole-3-carbinol and 3,3'-diindolylmethane induce apoptosis in human prostate cancer cells," Food and Chemical Toxicology, vol. 41, no. 6, pp. 745-752, 2003.

[29] J. V. Higdon, B. Delage, D. E. Williams, and R. H. Dashwood, "Cruciferous vegetables and human cancer risk: epidemiologic evidence and mechanistic basis," Pharmacological Research, vol. 55, no. 3, pp. 224-236, 2007.

[30] N. Van Belzen, W. N. M. Dinjens, M. P. G. Diesveld et al., "A novel gene which is up-regulated during colon epithelial cell differentiation and down-regulated in colorectal neoplasms," Laboratory Investigation, vol. 77, no. 1, pp. 85-92, 1997.

[31] K. Jiang, Z. Shen, Y. Ye, X. Yang, and S. Wang, "A novel molecular marker for early detection and evaluating prognosis of gastric cancer: N-myc downstream regulated gene-1 (NDRG1)," Scandinavian Journal of Gastroenterology, vol. 45, no. 7-8, pp. 898-908, 2010.

[32] T. Ando, H. Ishiguro, M. Kimura et al., "Decreased expression of NDRG1 is correlated with tumor progression and poor prognosis in patients with esophageal squamous cell carcinoma," Diseases of the Esophagus, vol. 19, no. 6, pp. 454-458, 2006.

[33] M. Iiizumi, W. Liu, S. K. Pai, E. Furuta, and K. Watabe, "Drug development against metastasis-related genes and their pathways: a rationale for cancer therapy," Biochimica et Biophysica Acta, vol. 1786, no. 2, pp. 87-104, 2008.

[34] L. Teimoori-Toolabi, K. Azadmanesh, A. Amanzadeh, and S. Zeinali, "Selective suicide gene therapy of colon cancer exploiting the urokinase plasminogen activator receptor promoter," BioDrugs, vol. 24, no. 2, pp. 131-146, 2010. 

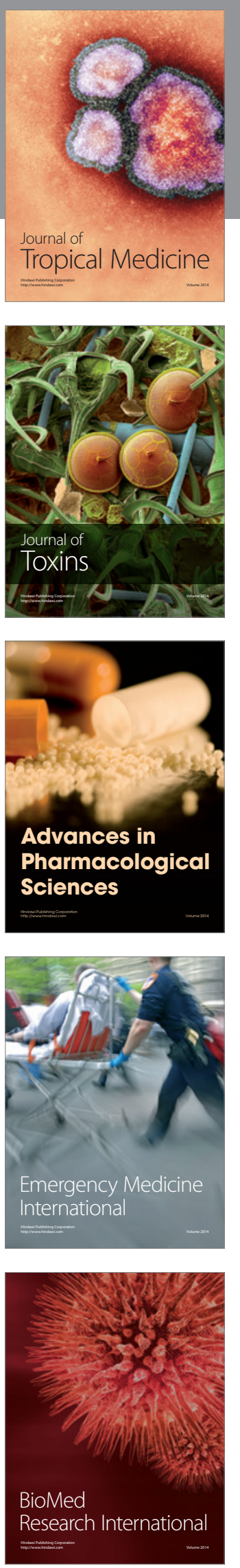
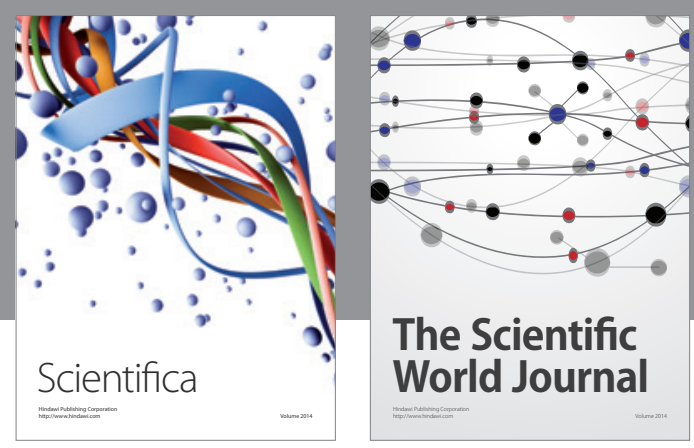

The Scientific World Journal
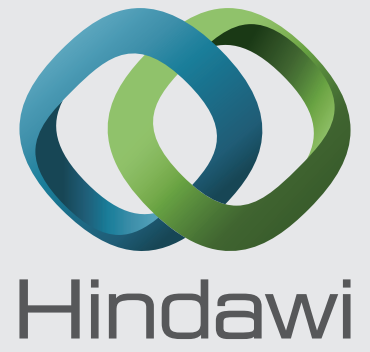

Submit your manuscripts at

http://www.hindawi.com
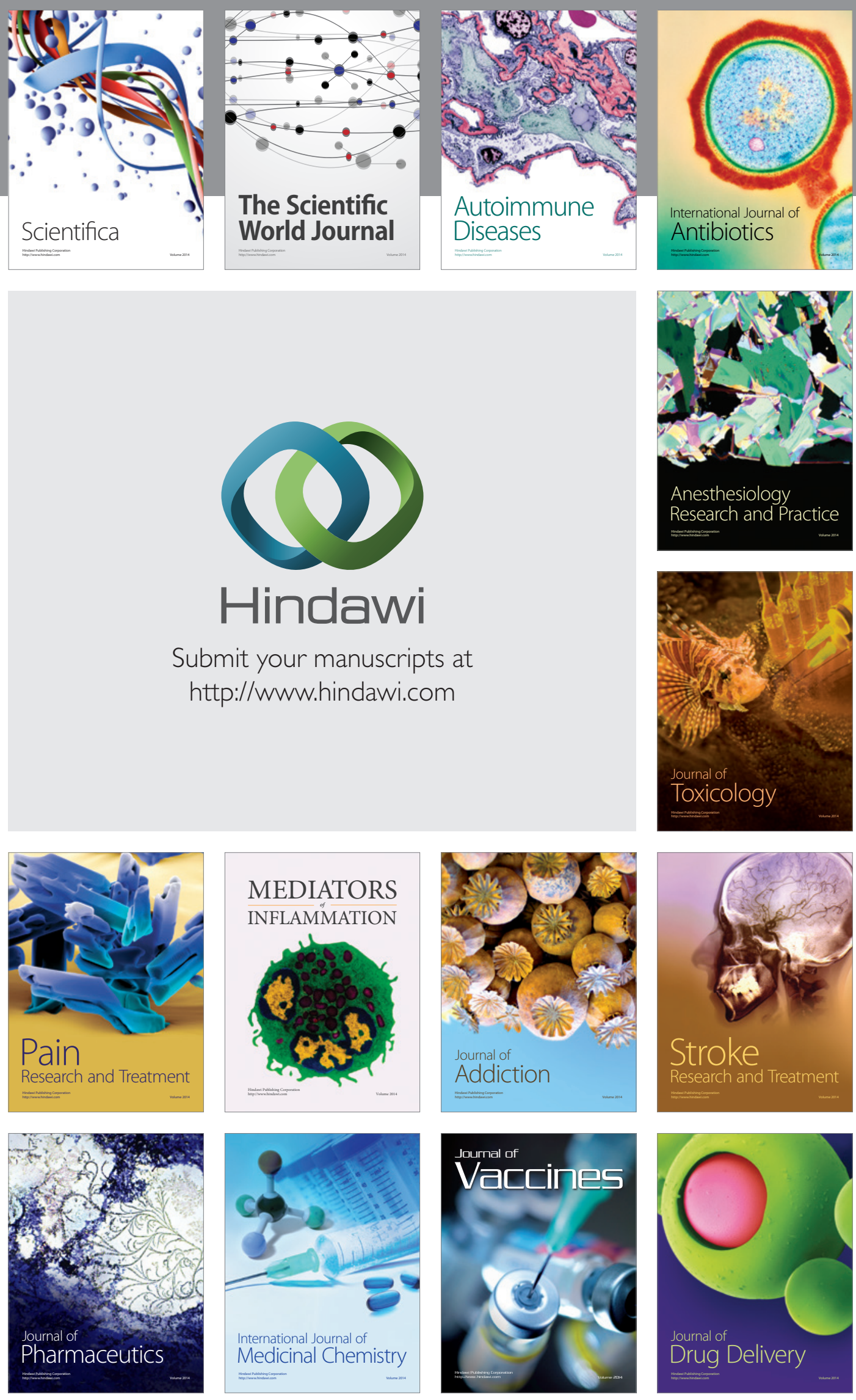